\title{
A field study to determine prevalence and fresh cow clinical conditions associated with sub-clinical ketosis in Central Eastern European dairy herds
}

\author{
Anna Catharina Björnsdotter Berge* \\ Department of Reproduction, Obstetrics and Herd Health, Ghent University, Belgium
}

\begin{abstract}
The study reported in this short communication aimed to determine prevalence, major management systems and fresh cow clinical conditions associated with subclinical ketosis (SCK) in Central Eastern European dairy herds. A total of 1751 cows in 64 herds were enrolled in Austria, Czech Republic, Hungary and Poland between November 2012 and September 2014. A milk-based test for ketones (Keto-TestTM) was used for screening cows between 7-21 days after calving and SCK was defined as Keto-Test $\geq 100 \mu \mathrm{mol} / \mathrm{l}$. Study herds recorded fresh cow clinical conditions. Multivariate analysis (GEE logistic regression) was performed to determine country, farm, management, feed and cow factors associated with SCK and to determine associations between SCK and fresh cow diseases. This study indicated that the odds of SCK are 50\% higher in multiparous cows compared to primiparous cows, and the odds of SCK was twice as high in Poland compared to Austria, whereas there was no significant difference in risks of SCK between Austria, Hungary and the Czech republic. A cow with calving difficulties (dystocia, twins or abortion) was 2.8 times more likely to screen positive for SCK, compared to cows with normal calving events. Fresh cow diseases were found to be at least twice as common in cows with SCK compared to cows with no SCK. It was noted that only six of the 93 cows with milk ketones $\geq 500 \mu \mathrm{mol} / 1$ were diagnosed with clinical ketosis, indicating that clinical ketosis diagnosis is often missed.
\end{abstract}

\section{Introduction}

Subclinical ketosis (SCK) is a common metabolic disorder that affects lactating dairy cows, and its prevalence in Europe is estimated to be in the range $22-37 \%$ [1-3]. Numerous studies evaluating the associations between SCK and various fresh cow diseases indicates that SCK is associated with an increased risk of developing fresh cow conditions and reduced milk production. A meta-analysis of 23 studies estimated a relative risk of 1.8 for metritis, 1.5 for retained placenta, 3.3 for displaced abomasum, 5.4 for clinical ketosis, 1.9 for early culling and death [2]. In addition to these risks, a western European study indicated that risks for mastitis, paresis, lameness, and gastrointestinal disease increased in fresh cows diagnosed with SCK [1]. This study also noted that at the time of diagnosis 47 to $90 \%$ of the individual fresh cow clinical conditions were associated with SCK. SCK has an economic impact on the herd due to decreased milk production, increased incidence and duration of fresh cow diseases, increased time to conception and an increased risk of culling. The total costs of SCK in European systems were estimated with stochastic methods at 257 Euro in a dairy herd with $10,000 \mathrm{Kg} 305$-day milk production [4].

The Keto-Test ${ }^{\text {is }}$ (Ketolac test strip) is a cow-side milk test used for screening for ketosis and when using a milk cut point of $100 \mu \mathrm{mol}$ $\beta$-hydroxybutyrate (BHBA)/L as indicative of SCK it corresponds to a serum range of 1.0-1.4 mmol BHBA/L. The sensitivity of the test has been estimated at $83 \%$ and the specificity at $82 \%[5,6]$.

This cross-sectional longitudinal field study aimed to determine SCK prevalence, management systems and fresh cow clinical conditions associated with SCK in four central eastern European country dairy herds. The null hypothesis was that SCK was not significantly associated with any fresh cow clinical conditions.

\section{Material and methods}

This study followed the same methodology as previously described for western European countries [1]. Fifty-six study herds, in Czech Republic, Poland, Hungary and Austria were enrolled by participating veterinarians between Nov 2013 and Sep 2014. No routine ketosis prevention or treatment was used in the herds. All calving cows in the selected herds were included and enrolled for a period of 1 to 2 months. The Keto-Test strip was used where outcomes were categorized in nominal levels of $0,50,100,200,500$, and $1000 \mu \mathrm{mol}$ of BHBA/l of milk respectively and $100 \mu \mathrm{mol} / \mathrm{l}$ or higher was defined as SCK. The Keto-Test was used 7-21 days post calving and observations for clinical disease performed by the farm staff $0-35$ days post calving. Diagnosis of cow conditions was according to clinical symptoms and definitions that were provided to participating veterinarians and farmers. A logistic regression model with a generalized estimating equation (GEE logistic model) was used to determine herd level factors associated with odds of ketosis while control for clustering of farms within a country. Relationships between ketosis in the study screening (7-21 days postpartum) and clinical disease within 35 days post-partum was analyzed

*Correspondence to: Anna Catharina Berge, Department of Reproduction, Obstetrics and Herd Health, Faculty of Veterinary Medicine, Ghent University, Salisburylaan 133, 9820 Merelbeke, Belgium, Tel: 0032-54243554; E-mail: anna.berge@ugent.be

Key words: sub-clinical ketosis, peri-parturient disease, dairy cows

Received: February 06, 2020; Accepted: March 02, 2020; Published: March 05, 2020 
using separate clinical disease specific GEE logistic models controlling for clustering of cows within farms and including significant covariates. For clinical conditions dystocia, twins, RP and milk fever the predictive variable was the clinical condition and the outcome dependent variable was SCK. For metritis, mastitis, clinical ketosis, DA, lameness and GIdisease the predictive variable was SCK at screening and the outcome variable was the clinical condition.

\section{Results}

This study included 1751 fresh cows in 64 herds enrolled between November 2012 to March 2014 (Table 1). The study cows were 35\% heifers, $25 \%$ parity 2 and $40 \%$ parity $3-10$. The average time for the Keto-Test was 13 days in milk. Of the 1751 cows the Keto-Tests results were; $38 \%$ had $0 \mu \mathrm{mol} / 1,22 \%$ had $50 \mu \mathrm{mol} / \mathrm{l}, 24 \%$ had $100 \mu \mathrm{mol} / \mathrm{l}, 10 \%$ had $200 \mu \mathrm{mol} / \mathrm{l}, 4 \%$ had $500 \mu \mathrm{mol} / \mathrm{l}$ and $2 \%$ had $1000 \mu \mathrm{mol} / \mathrm{l}$ (Table 2). Overall, $40 \%$ of the cows were classified as having SCK (which included those that had clinical ketosis) (Table 1). The herd level prevalence of SCK was 38\% in Austria, 34\% in Czech Republic, $40 \%$ in Hungary and $63 \%$ in Poland (Table 1). Of the 64 farms, 50 (78\%) had $25 \%$ or more of their fresh cows with SCK. Clinical ketosis was only reported in 7 farms.

The GEE logistic regression model indicated that the odds of SCK were 1.5 times higher in parity 2 and parity 3-10 compared to parity 1 (Table 3). Housing system, management system, feeding system, lactating herd size, average yearly production per cow, the number of days in milk (7 to $21 \mathrm{DIM}$ ) at the time of screening, calving quarter of year were not significantly associated with SCK. The odds of SCK were twice as likely in Poland compared to Austria, whereas there was no significant difference in odds of SCK in Czech Republic and Hungary compared to Austria (Table 3).
Diseases in study cows within 35 days of calving were recorded in 1418 cows of 49 herds ( 1 district in Austria and one in Poland failed to record fresh cow diseases). The most common conditions reported were metritis ( $4.8 \%$ of cows), followed by retained placenta (4.4\%), mastitis (3.4\%), dystocia (2.8\%), milk fever (1.7\%), clinical ketosis and lameness (1.5\%), gastro-intestinal disorder (1.4\%) and displaced abomasum (1.1\%) (Figure 1). The separate GEE logistic models indicated that SCK in study cows was significantly associated with increased risk of fresh cow conditions (Table 4). A cow with calving difficulties (dystocia, twins or abortion) was 2.8 times more likely to screen positive for SCK $(\mathrm{OR}=2.8$, P-value $<0.01)$. A cow with dystocia was 3.4 times more likely to have SCK and a cow with twins was 2.4 times more likely to have SCK.

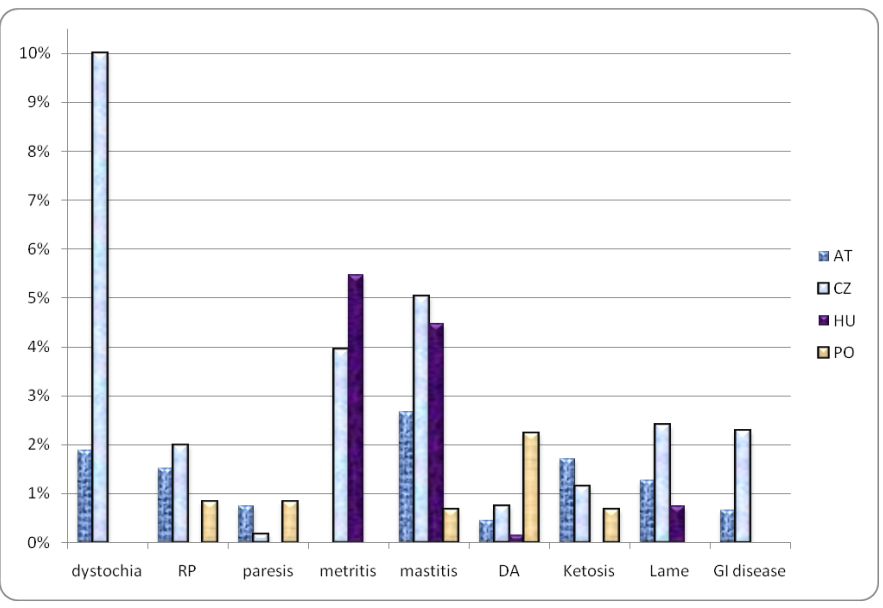

Figure 1. Farm prevalence of fresh cow clinical conditions in 49 dairies in a study of subclinical ketosis in dairy cows in 4 Central Eastern European countries

Table 1. Dairy herds enrolled in study of sub-clinical ketosis in Central Eastern European dairy cows

\begin{tabular}{|c|c|c|c|c|c|c|c|}
\hline \multirow[b]{2}{*}{ Country } & \multirow{2}{*}{$\begin{array}{c}\text { Dairies } \\
\text { No }\end{array}$} & \multicolumn{2}{|c|}{ Lactating herd size } & \multirow{2}{*}{$\begin{array}{l}\text { Parity } \\
\text { Mean }\end{array}$} & \multirow{2}{*}{$\begin{array}{l}\text { DIM }^{1} \\
\text { Mean }\end{array}$} & \multicolumn{2}{|c|}{ Herd prevalence $\mathrm{SCK}^{2}$} \\
\hline & & Mean & Range & & & Mean & Range \\
\hline AT & 27 & 48 & $20-88$ & 3,0 & 13,0 & $38 \%$ & $0-100 \%$ \\
\hline $\mathrm{CZ}$ & 6 & 483 & $265-620$ & 2.3 & 13.8 & $34 \%$ & $1-67 \%$ \\
\hline $\mathrm{HU}$ & 8 & 1012 & $373-1500$ & 2,0 & 13.2 & $40 \%$ & $26-65 \%$ \\
\hline PL & 23 & 293 & $25-697$ & 2.4 & 13.6 & $63 \%$ & $9-100 \%$ \\
\hline
\end{tabular}

1. DIM = Days in milk

2. SCK $=$ Sub-clinical ketosis

Table 2. Results of Keto-Test ( $\mu \mathrm{mol} / 1$ milk) screening of transition cows 7-21 DIM in 64 Central Eastern European dairy herds

\begin{tabular}{|c|c|c|c|c|c|c|c|c|}
\hline Country & Cows & $\mathbf{0}$ & 50 & 100 & 200 & 500 & 1000 & $\% \geq 100$ \\
\hline AT & 394 & 183 & 74 & 100 & 27 & 8 & 2 & $35 \%$ \\
\hline $\mathrm{CZ}$ & 421 & 198 & 87 & 77 & 38 & 17 & 4 & $32 \%$ \\
\hline $\mathrm{HU}$ & 478 & 174 & 119 & 112 & 46 & 20 & 7 & $39 \%$ \\
\hline PL & 458 & 106 & 106 & 138 & 67 & 21 & 20 & $54 \%$ \\
\hline Sum & 1751 & 661 & 386 & 427 & 178 & 66 & 33 & $40 \%$ \\
\hline$\%$ cows & & $38 \%$ & $22 \%$ & $24 \%$ & $10 \%$ & $4 \%$ & $2 \%$ & \\
\hline
\end{tabular}

Table 3. Logistic regression odds ratios for sub-clinical ketosis in transition dairy cows in four Central Eastern European countries

\begin{tabular}{|c|c|c|c|c|c|c|}
\hline Parameter & Comparison & Odds ratio & S.E. & Lower CI & Higher CI & P-value \\
\hline \multirow[t]{3}{*}{ Parity } & 1 & ref & & -- & -- & ref. \\
\hline & 2 & 1.46 & 1.14 & 1.12 & 1.90 & $<0.01$ \\
\hline & $3-8$ & 1.47 & 1.15 & 1.11 & 1.94 & $<0.01$ \\
\hline \multirow[t]{4}{*}{ Country } & AT & ref & & -- & -- & ref. \\
\hline & $\mathrm{CZ}$ & 0.91 & 1.89 & 0.26 & 3.17 & 0.89 \\
\hline & $\mathrm{HU}$ & 1.26 & 1.28 & 0.78 & 2.04 & 0.34 \\
\hline & $\mathrm{PO}$ & 2.18 & 1.38 & 1.16 & 4.10 & 0.02 \\
\hline
\end{tabular}


Table 4. Odds of sub-clinical ketosis in 10 separate logistic regression models for transition cow conditions in 4 Eastern European countries

\begin{tabular}{|c|c|c|c|c|c|}
\hline Dependent factor & Odds ratio $^{1}$ & S.E & Lower CI & Higher CI & P-value \\
\hline Metritis & 1.0 & 0.72 & 0.2 & 4.2 & 0.97 \\
\hline Clinical ketosis ${ }^{2}$ & & & & & $<0.01$ \\
\hline Mastitis & 2.3 & 0.7 & 1.3 & 4.0 & $<0.01$ \\
\hline GI disease & 6.9 & 6.4 & 1.1 & 42.6 & 0.04 \\
\hline Lameness & 2.8 & 1.4 & 1.0 & 7.4 & 0.04 \\
\hline DA & 3.4 & 1.8 & 1.2 & 9.6 & 0.02 \\
\hline Predictive factor & Odds ratio $^{1}$ & S.E & Lower CI & Higher CI & P-value \\
\hline Retained placenta & 2.1 & 0.9 & 1.0 & 4.8 & 0.07 \\
\hline Paresis & 4.9 & 1.9 & 2.3 & 10.2 & $<0.01$ \\
\hline Dystocia & 3.4 & 1.0 & 1.9 & 6.1 & $<0.01$ \\
\hline Twins & 2.4 & 1.5 & 0.7 & 8.3 & 0.17 \\
\hline
\end{tabular}

1. The odds ratio represents the odds that a cow diagnosed with sub-clinical ketosis was diagnosed with the condition compared to a cow with no sub-clinical ketosis.

2. There was no clinical ketosis in cows without sub-clinical ketosis, Fisher Exact P-value presented.

Fresh cow diseases were found to be twice as common (OR=2.09, $\mathrm{P}$-value $=0.05)$ in cows with SCK compared to cows with no SCK at screening 7-21 days post calving (Table 4). A cow with a Keto-Test indicating SCK was 2.1 times more likely for retained placenta, 3.4 times more likely for displaced abomasum, 4.8 times more likely for paresis, 2.3 times more likely for mastitis, 2.8 times more likely for lameness, 6.9 times more likely for gastrointestinal disease in the first 35 days postcalving. There was no significant increase in odds of metritis. It was noted that only 2 of the 64 cows with a Keto-Test of $500 \mu \mathrm{mol} / \mathrm{l}$ and only 4 of 29 cows with $1000 \mu \mathrm{mol} / \mathrm{l}$ were diagnosed with clinical ketosis. This indicates that clinical cases of ketosis were likely not diagnosed.

\section{Discussion}

This study indicates that SCK is highly prevalent in dairy herds in Austria, Czech Republic, Hungary and Poland and at similar levels as many other EU countries and is associated with at least a two-fold increase in risk of fresh cow diseases [1].

The definition of what appropriate tests and levels of ketones are considered sub-clinical ketosis continues to be discussed. In a recent study it was confirmed that Beta-hydroxybutyrate in milk is a good indicator of sub-clinical ketosis in dairy cows [7]. In that study the authors considered that a cut-point for sub-clinical ketosis corresponding to BHBA $\geq 80 \mu \mathrm{mol} / \mathrm{L}$ is a significant indicator for subclinical ketosis and the sensitivity of the test was $94 \%$ and specificity $74 \%$ [7]. In our study SCK was defined as Keto-Test BHBA $\geq 100$ $\mu \mathrm{mol} / \mathrm{l}$. A lower specificity than our chosen cut-point will increase the number of false positive cows and might have resulted in even higher prevalence of sub-clinical ketosis. A lower cut-point will on the other hand decrease associations between SCK and fresh cow diseases. There is no correct answer, and regardless of chosen cut points, the evidence from this study indicates that SCK in CEE EU dairy cows is highly prevalent and a high risk for fresh cow diseases.

The herds were a convenience sample enrolled as typical herds of the regions and throughout the participating countries and the country prevalence estimates is believed to reflect the situation in the countries. Numerous factors affect prevalence estimated of SCK such as method of detection, cut-points, time intervals for monitoring, parity groups monitored etc. Our study indicates that the prevalence of SCK in these 4 European countries were in the range as reported using the same study design for Western European countries [1]. This study indicates higher national prevalence estimates (Hungary 40\% and Poland 63\%) than those reported by Suthar et al. (Hungary $15.6 \%$ and Poland 19.4\%), however different screening times, methodologies and cut points were used.
The herd level risk factors previously detected in previous studies were not detected in this study. This may be due to the power of the study and the distribution of farm management systems across the various countries sampled. No statistical association between increasing lactating herd size and decreasing prevalence of ketosis was detected as previously described. However, the herd size might be confounded with other factors and the herd size effect is likely linked to management and nutrition systems on farm. It has been hypothesized that larger herd size may facilitate more appropriate heifer, dry cow and lactation stage diet specificity and a higher involvement of nutritional services. It was noted that many Polish dairy farms were relatively small, and Poland had a high prevalence of ketosis (63\%) compared to other EU countries in this study and the prevalence estimates reported previously [1]. This study did not detect any association between feeding, housing or management practices and increased risks of SCK and this contrasts with the study in the Western European countries where less SCK was noted in herds using total mixed ration or feeding forage and concentrate separate compared to part mixed ration [1]. Other studies have found that levels of SCK are higher in automatic milking robot systems and speculate that the feeding system could be a factor [8]. This study may not have had the farm management distributions to detect similar associations, or it may be that there may be other farm level factors that confound the results of either this study or previous studies, such as age at first calving, calving intervals, length of dry period and body condition scoring [8]. Further studies are needed to determine associations between feeding management and SCK. This study could not find an association between previous lactation production and SCK, as described elsewhere, but our data did not include calving interval and 305 day milk production, which are factors that have been shown to be associated with SCK $[8,9]$.

This study did not allow evaluation of seasonal effect of ketosis due to that enrollment of farms in the different countries did not span all four seasons. Previous studies have found higher levels of SCK in the spring compared to the autumn $[1,3]$ and in a study in Ontario, lower levels of SCK were noticed in the period July to November [8].

This study confirms that the lowest prevalence of SCK was found in primiparous cows, and it was significantly higher in multiparous cows. Several studies have similarly found that ketosis is more frequent in multiparous cows compared to primiparous cows $[1,3,9]$. The increased SCK risk in multiparous cows compared to primiparous cows may be due to depletion of energy reserves in previous lactation through combined gestation and lactation.

This study reinforces the clear association between SCK postpartum and clinical disease is shown by numerous previous studies 
[1-3]. Our study did not allow for us to determine the temporal relationships between disease diagnosis and SCK screening. Since SCK has been shown to be present pre-partum and in the fresh cow period, the temporal relationships are difficult to evaluate in this type of field study. Furthermore, for temporal associations, multiple sampling times through the fresh cow period are necessary, as SCK can be of shorter or longer duration. The cut-point for definition of SCK can greatly affect the strength of the associations with fresh cow conditions, and it has been recommended that $1.4 \mathrm{mmol} \mathrm{BHBA} / \mathrm{L}$ serum is appropriate [2]. Our Keto-Test cut-point of $1.0 \mathrm{mmol} / \mathrm{L}$ milk corresponding to $1.0-1.4$ $\mathrm{mmol} / \mathrm{L}$ serum, and it may over-estimate prevalence and underestimate disease associations [5]. On the other hand, a study of 100 dairy herds in USA indicated that peak BHBA levels were found at 5 DIM and the median time in SCK was 5 days [10]. Our study may thereby underestimate prevalence of SCK and the association with fresh cow clinical disease levels by using a single sampling on average 13 DIM with a range of 6-21 DIM. Regardless of exact cut-point and time of SCK testing, the picture remains clear that SCK is associated with at least a doubling in risk for fresh cow clinical diseases. Many of these diseases such as mastitis, metritis and lameness will involve antimicrobial use, with associated risk for antimicrobial resistance. It is very important to use a holistic approach to reducing prophylactic and therapeutic antibiotics on dairies. Therefore, addressing the metabolic and nutritional challenges of the transition period is necessary to reduce fresh cow diseases associated with high antimicrobial use.

\section{Conclusion}

This study in four central eastern European Countries, confirms that SCK continues to be a highly prevalent in our modern dairy herds and the strong links with fresh cow diseases and reduced production warrant active surveillance and preventive management measures.

\section{Acknowledgement}

This study author thanks contributing veterinarians and dairy owners for their participation.

\section{Funding information}

This study was financially supported by Elanco Animal Health.

\section{Competing interests}

The study author has no competing interests.

\section{References}

1. Berge AC, Vertenten G (2014) A field study to determine the prevalence, dairy herd management systems, and fresh cow clinical conditions associated with ketosis in western European dairy herds. J Dairy Sci 97: 2145-2154. [Crossref]

2. Raboisson D, Mounie M, Maigne E (2014) Diseases, reproductive performance, and changes in milk production associated with subclinical ketosis in dairy cows: A metaanalysis and review. J Dairy Sci 97: 7547-7563. [Crossref]

3. Suthar VS, Canelas-Raposo J, Deniz A, Heuwieser W (2013) Prevalence of subclinical ketosis and relationships with postpartum diseases in European dairy cows. J Dairy Sci 96: 2925-2938. [Crossref]

4. Raboisson D, Mounie M, Khenifar E, Maigne E (2015) The economic impact of subclinical ketosis at the farm level: Tackling the challenge of over-estimation due to multiple interactions. Prev Vet Med 122: 417-425. [Crossref]

5. Oetzel GR (2004) Monitoring and testing dairy herds for metabolic disease. Vet Clin North Am Food Anim Pract 20: 651-674. [Crossref]

6. Tatone EH, Gordon JL, Hubbs J, LeBlanc SJ, DeVries TJ, et al. (2016) A systematic review and meta-analysis of the diagnostic accuracy of point-of-care tests for the detection of hyperketonemia in dairy cows. Prev Vet Med 130: 18-32. [Crossref]

7. Jezek J, Cincovic MR, Nemec M, Belic B, Djokovic R, et al. (2017) Betahydroxybutyrate in milk as screening test for subclinical ketosis in dairy cows. Pol $J$ Vet Sci 20: 507-512. [Crossref]

8. Tatone EH, Duffield TF, LeBlanc SJ, DeVries TJ, Gordon JL (2017) Investigating the within-herd prevalence and risk factors for ketosis in dairy cattle in Ontario as diagnosed by the test-day concentration of beta-hydroxybutyrate in milk. $J$ Dairy $S c i$ 100: 1308-1318. [Crossref]

9. Vanholder T, Papen J, Bemers R, Vertenten G, Berge AC (2015) Risk factors for subclinical and clinical ketosis and association with production parameters in dairy cows in the Netherlands. J Dairy Sci 98: 880-888. [Crossref]

10. McArt JA, Nydam DV, Oetzel GR (2012) Epidemiology of subclinical ketosis in early lactation dairy cattle. J Dairy Sci 95: 5056-5066.[Crossref]

Copyright: (C2020 Berge AC. This is an open-access article distributed under the terms of the Creative Commons Attribution License, which permits unrestricted use, distribution, and reproduction in any medium, provided the original author and source are credited. 